\title{
Diagnosis of Fetal Facial and CNS Malformations during Mid-Trimester Anomaly Scan: Does Three-Dimensional Ultrasonography Have Any Added Value?
}

\author{
AMR A.A.M. GBR, M.Sc.*; HOSSAM ELDIN MANSOUR ABDELRAHMAN, M.D.*; \\ SAID ABDELMONEM EBRAHIM, M.D.* and DALIA O. EL-HAIEG, M.D.** \\ The Departments of Radiodiagnosis* and Obstetrics \& Gynecology**, Faculty of Medicine, Zagazig University, Egypt
}

\begin{abstract}
Background: The ability of three dimensional ultrasound to acquire and save volume datasets, reconstruct any plane in the volume and allow off-line re-examination and manipulation of these datasets, makes this technology superior to two dimensional ultrasound in many areas.
\end{abstract}

Aim of Study: This study was conducted to determine if there is any added value of 3D US examination in diagnosis of fetal malformations during mid-trimester anomaly scan.

Subject and Methods: Pregnant women referred for midtrimester anomaly scan were prospectively evaluated by $2 \mathrm{D}$ US. Fetuses suspected to have malformation by $2 \mathrm{D}$ US or with increased risk of a recurrence or strong family history of a congenital abnormality, were evaluated by 3D US. Women confirmed to have fetal malformations postnatally were included.

Results: Sixty malformations were confirmed postnatally. 2D US established the diagnosis of fifty seven $(95 \%)$ malformations and two malformations were detected exclusively by $3 \mathrm{D}$ US, and the difference was highly significant $[\mathrm{McNemar}$ chi-squared statistic $=18, p=<0.0001]$. Fifty nine malformations were diagnosed by both $2 \mathrm{D}$ and 3D US.

Conclusions: 3D US significantly improved the number of detected fetal malformations, than that detected by 2D US $3 \mathrm{D}$ imaging is superior in specific diagnostic problems. Rather than representing an alternative, 3D US is complementary to the conventional 2D US in the field of prenatal diagnosis.

Key Words: Ultrasound-Two-dimensional-Threedimensional - Fetal malformations.

\section{Introduction}

THREE-DIMENSIONAL (3D) ultrasound imaging permits examiners to replace the imaginary reconstruction of two-dimensional (2D) images to actual 3D visualization of anatomical structures [1]. By definition, 3D ultrasonography (3D US)

Correspondence to: Dr. Amr A.A.M. Gbr, The Department of Radiodiagnosis, Faculty of Medicine, Zagazig University, Egypt contains an infinite number of 2D scan planes, which can be displayed in three orthogonal planes starting with any orientation. The ability to display a volume in planes in which direct image acquisition is not possible represents the most important advance that 3D US has to offer [2]. 3D US is also beneficial in affording the ability of postexamination interactive review, the availability of a variety of rendering methods that allow visualization of different characteristics of the same structure and the possibility of rotating the volume database and examine anatomical structures from different views and in reconstructed planes. Moreover, volume measurements are more accurate, including volume measurements of irregular objects, and imaging of the fetal skeleton and spatial presentation of blood vessels arborization are much improved. Furthermore, encouraging the bond between the mother and her fetus, the possibility to standardize ultrasound examinations, the ability to transmit data over networks for consultation in tertiary care centers and the potential to use offline software programs as an interactive educational tool, adds to the value of 3D US [3-8].

To be incorporated to the daily clinical practice, 3D US will require, however, more than visually appealing images or praise regarding the diagnostic possibilities of this technology. Wide acceptance will come if there is a scientific evidence that 3D US adds information to what is currently provided by 2D US. Some of the studies found that 3D US was advantageous for the visualization of congenital malformations $[\mathbf{9 , 1 0}]$, whereas others found that $3 \mathrm{D}$

\footnotetext{
Abbreviations:

2D US : Two Dimensional Ultrasound.

3D US : Three Dimensional Ultrasound.

TUI : Tomographic Ultrasound Imaging.
} 
US did not provide significant additional information over what was provided by 2D US [11], thus further investigations are required to come to a consensus.

\section{Patients and Methods}

From September 2018 to February 2019, cross sectional study was done on 1600 pregnant women referred to Zagazig University Hospitals for midtrimester anomaly scan with with malformations confirmed postnatally in 60 women. 167 fetuses (147 singleton and 10 pairs of twins) with a total of 180 confirmed malformations were included in the study. The mean age of the 167 women was 29.8 years (range, $21-40$ years), and the mean gestational age of the fetuses at sonographic examination was 22 weeks (range, 20-25).

Ethics approval and consent to participate: This study was approved by the institutional review board of Zagazig University. An informed oral consent was taken from all cases included in the study.

\section{Procedure:}

Both 2D US and 3D US were done using a Voluson E6 machine (GE Medical Systems, Zipf, Austria). A transabdominal convex array volume RAB6-D transducer was employed for 2D examination, and to acquire the volume dataset. Voluson 730 pro machine (GE Medical Systems, Zipf, Austria). A Transabdominal convex array volume RNA5-9-D H48651MY was employed for 2D examination and to acquire the volume dataset.

At first, all fetuses were scanned by using standard 2D US (by one sonographer) which was performed following the International Society of Ultrasound in Obstetrics and Gynecology (ISUOG) practice guidelines for performance of the routine mid-trimester fetal ultrasound scan [12]. An initial 2D Sonographic diagnosis of fetal malformations was established and recorded.

Representative 3D volume data sets of the fetal anatomy for fetuses suspected to have malformation by conventional 2D US or in cases with increased risk of a recurrence or strong family history of a congenital abnormality. During 3D volume acquisition, special attention was paid to the biophysical prerequisites to ensure an optimal image quality, absence of fetal movements, favorable position of the region of interest in relation to the probe and sufficient amount of amniotic fluid around the region of interest. Approximately 2 to 5 volume data sets were obtained per anomaly. The goal of the examination was to document fetal anatomical structures and congenital malformations as thoroughly as possible. Volume data were stored on the hard drive of the US machine.

\section{Review of images:}

Later, volume data sets were processed and examined for each patient by another sonographer who was blinded to the result of 2D examination, in order to establish a diagnosis by 3D US. The 3D US volume data were displayed in three modes: The multiplanar mode, rendering modes and Tomographic Ultrasound Imaging (TUI). The multiplanar images were rotated with the interactive display around the three axes (X, Y, or Z) into a standard anatomic orientation to display simultaneously the sagittal, transverse and coronal planes through the fetus at the region of interest; these could then be interactively studied by navigation through each plane independently. Rendered images were obtained by isolating a sub-volume of interest using a rectangular box in each of the three planes. After selection of the volume rendering mode, 3D image of the region of interest was displayed on the monitor. Volume manipulation for the achievement of high quality images included the electronic scalpel and threshold as well as brightness and contrast adjustments. Four types of 3D US volumerendering display algorithms were used: Surface rendering/HDlive, maximum mode and minimum mode/glass body Mode combined with color or power Doppler. The surface rendering/Hdlive images showed a smoothly contoured lifelike view, which was used to evaluate the facial features and extremities. The surface mode was also used to demonstrate internal structures when parts of the fetal anatomy were removed by the electronic scalpel to render the surface of the selected section. The inner bone structures were highlighted on the maximum mode images, which enabled visualization of the skeleton especially the spine, ribs and scapulae with higher contrast. The combined glass body/color or Doppler mode was used to demonstrate the fetal vascular system. Utilizing TUI, multiple slices of the acquired volume of the studied region were generated, enabling accurate mapping of the malformation aided by modifying the distance between and number of slices. Figs. (1-3) show some malformations visualized and studied by different modes of 3D US. The time needed for manipulating each patient's volumes into readable slices and surface rendered displays, lied between 10 and 30 minutes.

The final 3D US images were interpreted and recorded. Then they were compared to $2 \mathrm{D}$ US stored data (current standard fetal imaging). A subjective evaluation of whether the 3D US images 
were advantageous when compared with the 2D US findings was provided. The 3D technique was defined as advantageous when it provided additional information regarding localization, size and depth of a malformation, changes the diagnosis, or when a malformation undetected with 2D US was found.
In order to compare between the two modalities for the detection of fetal malformations, only, the patients who were confirmed to have fetal abnormalities by postnatal follow-up were included in the study. Confirmation of fetal malformations was performed by post-natal physical and/or radiological examinations as needed.

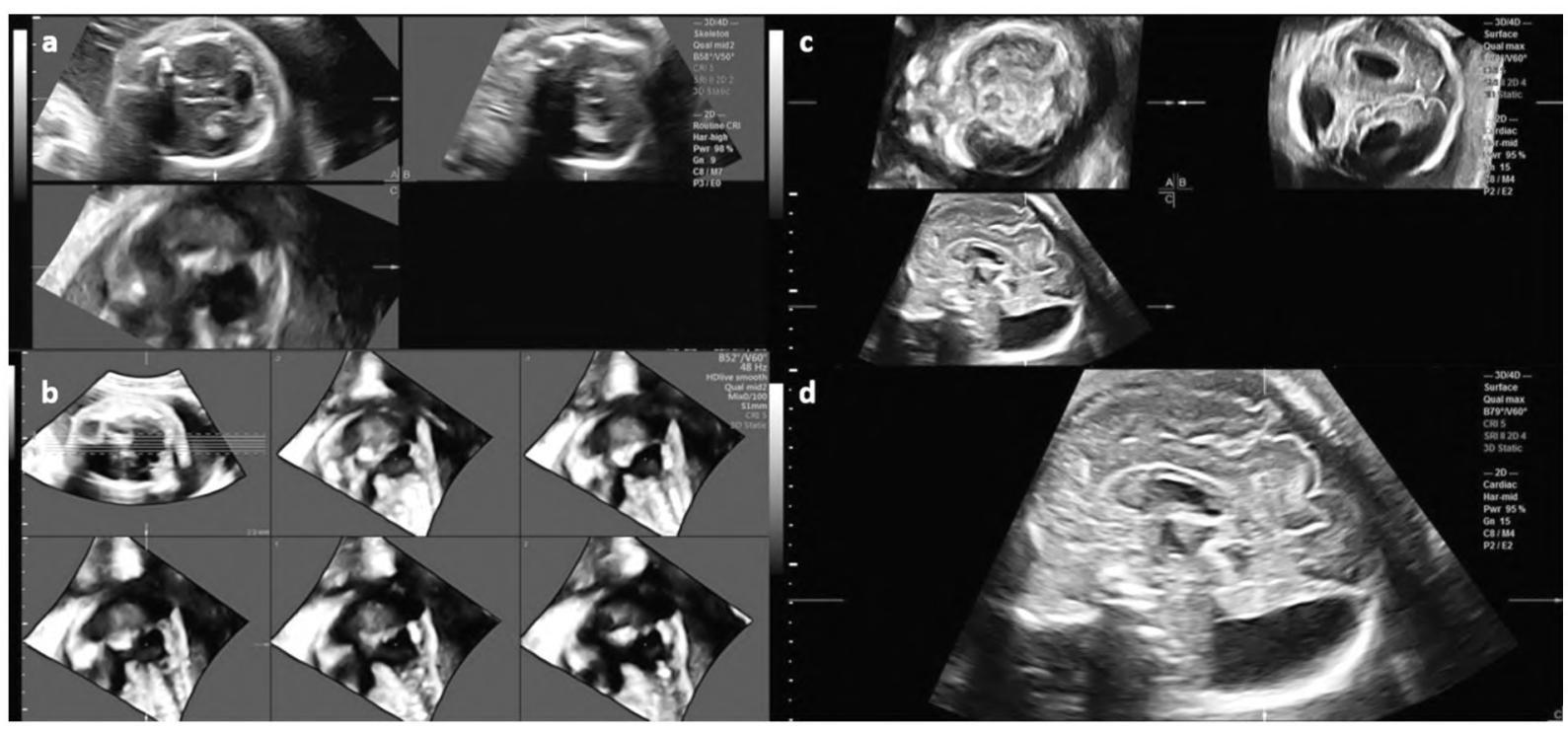

Fig. (1): 26 week diabetic pregnant female G3P2+1 was refered for anomaly scan shows Dandy-Walker malformation in multiplanar view (A) and Tomographic Ultrasound imaging (TUI) (B) Showing agenesis of the vermis, multiplanar view (C) and reconstructed mid-sagittal view of the brain (D) Showing upwards rotation of the hypoplastic vermis.
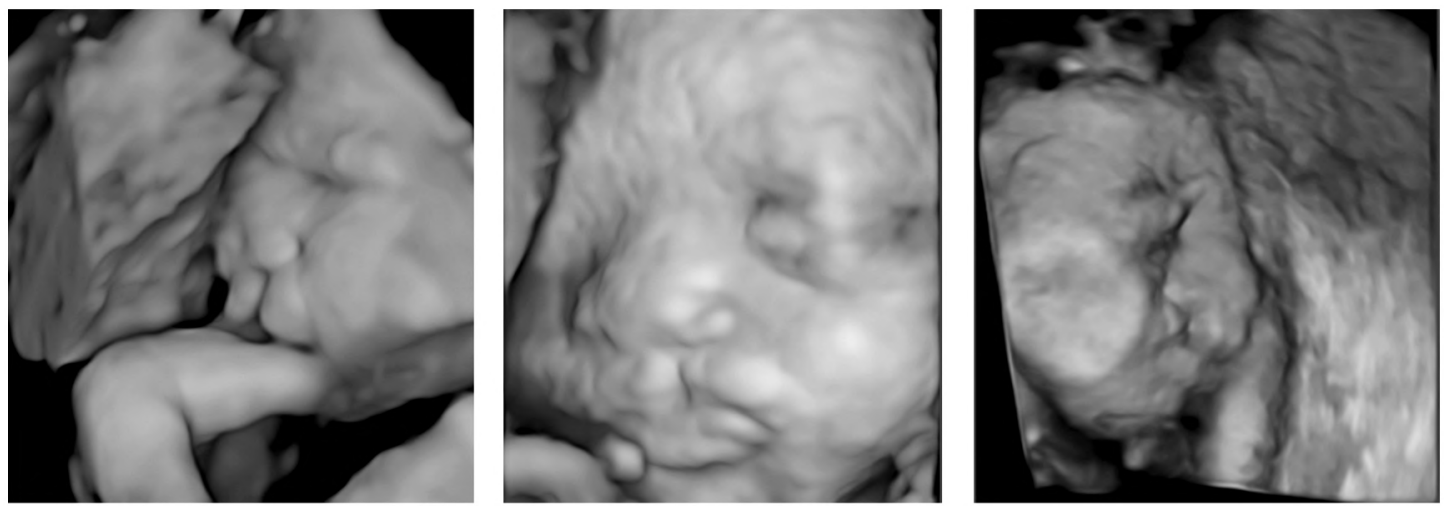

Fig. (2): 24 week pregnant female G5P3+2 with baby shows vleft lip in surface rendered mode.
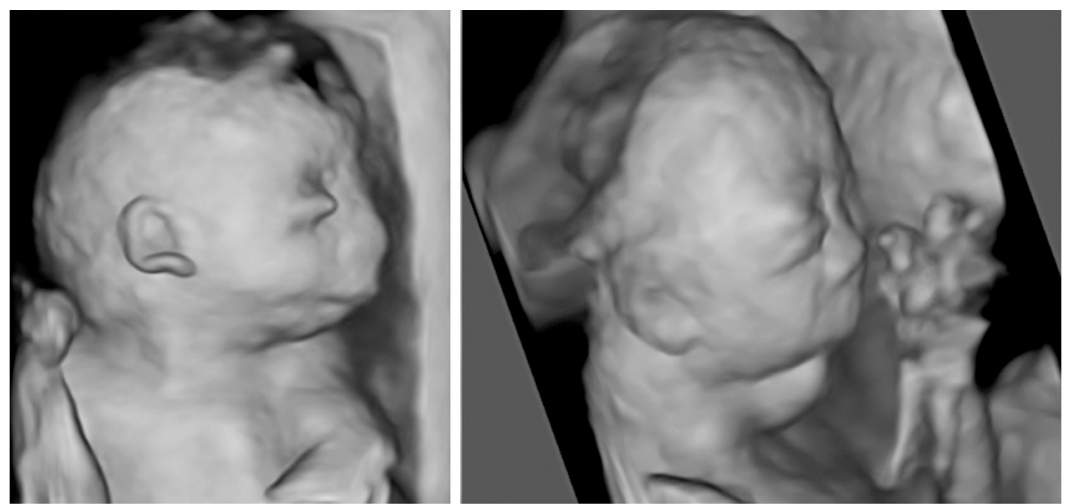

Fig. (3): 25 week primigravida pregnant female suspected to have Micrognathia by two dimensional ultrasound so three dimensional ultrasound was done (surface rendered mode). 


\section{Results}

2D US established the diagnosis of 57 (95\%) malformations, whereas, 3D US diagnosed 59 $(98.3 \%)$ malformations and the difference was highly significant $[\mathrm{McNemar}$ chi-squared statistic $=$ $18, p=<0.0001$ ] (Tables 1,2). The combined use of 2D US and 3D US perfectly diagnosed $98.3 \%$ of the malformations. In 2 malformations $(2.3 \%)$, the defects were detected exclusively by 3D US; agenesis of corpus callosum ( $\mathrm{n}=1)$, micrognathia $(\mathrm{n}=1)$. A cleft soft palate was missed by both $2 \mathrm{D}$ and 3D US. 3D US was particularly superior to $2 \mathrm{D}$ in evaluating cranial ( 1 out of 48 cases, $2 \%$ ) facial ( 1 out of $11,9 \%)$.

The differences between 2D US and 3D US in identifying fetal malformations were analyzed by McNemar test. Statistical significance was archived at a $p$-value of less than 0.05 . The statistical analysis was performed using SPSS $\odot$ Version 21 [IBMC Corp., Armonk, NY].

Table (1): Demographic data of the studied group.

\begin{tabular}{lcc}
\hline Variable & Studied group $(\mathrm{n}=1600)$ \\
\hline Age: & \multicolumn{2}{c}{$29.8 \pm 3.4$} \\
Mean \pm SD & No. & \\
\hline & & \\
Age (years): & 600 & 37.5 \\
20-25 & 460 & 28.7 \\
26-30 & 360 & 22.5 \\
$31-35$ & 180 & 11.2 \\
$36-40$ & & \\
Fetus: & 147 & 88.6 \\
Single & 20 & 11.4 \\
Twins & & \\
\hline
\end{tabular}

This table shows that the age of the studied participants ranged between 21 and 40 years with mean of 29.8 years. The highest frequency of them was at 20-25 years' age group (37.5\%) followed by age group $26-30(28.7 \%)$. About $88.6 \%$ of fetuses were single, while the remaining $11.4 \%$ of them were twins.

Table (2): Frequency distribution of head anomalies among the studied group.

\begin{tabular}{|c|c|c|}
\hline \multirow{2}{*}{ Variable } & \multicolumn{2}{|c|}{$\begin{array}{l}\text { Studied group } \\
\quad(\mathrm{n}=1600)\end{array}$} \\
\hline & No. & $\%$ \\
\hline \multicolumn{3}{|l|}{ Head anomalies: } \\
\hline No & 1540 & 96.3 \\
\hline Yes & 60 & 3.7 \\
\hline CNS anomalies & 48 & 80 \\
\hline Facial anomalies & 12 & 20 \\
\hline
\end{tabular}

This table shows that only $3.7 \%$ of the fetuses showed head anomalies discovered postnatally. Among the 60 fetuses, 48 had CNS anomalies $(80 \%)$ and the remaining 12 had facial anomalies $(20 \%)$.

Table (3): CNS anomalies among the studied group.

\begin{tabular}{llc}
\hline & \multicolumn{2}{c}{$\begin{array}{c}\text { Studied group } \\
(\mathrm{n}=48)\end{array}$} \\
\cline { 2 - 3 } Variable & No. & $\%$ \\
\hline Ventriculomegaly: & 15 & 31.2 \\
Anencephaly & 9 & 18.7 \\
Holoprosencephaly & 5 & 10.4 \\
Mega cisterna magna & 5 & 10.4 \\
Corpus callosum dysgenesis & 4 & 8.33 \\
Acrania: & 3 & 6.2 \\
Dandy walker malformation & 4 & 8.3 \\
Encephalocele & 2 & 4.1 \\
Hydranencephaly & 1 & 2.2 \\
\hline
\end{tabular}

This table shows that the majority of CNS anomalies was ventriculomegaly $(31.2 \%)$, the lowest frequency was one baby who was found to have hydranencephaly $(2.2 \%)$.

Table (4): Facial anomalies among the studied group.

\begin{tabular}{lcc}
\hline & \multicolumn{2}{c}{$\begin{array}{c}\text { Studied group } \\
(\mathrm{n}=12)\end{array}$} \\
\cline { 2 - 3 } Variable & No. & $\%$ \\
\hline Cleft lip and palate & 5 & 41.6 \\
Hypertelorism & 2 & 16.6 \\
Hypotelorism & 1 & 8.4 \\
Micrognathia & 3 & 25 \\
Low set ears & 1 & 8.4 \\
\hline
\end{tabular}

Table (5): Visualization of fetal malformation by 2D and 3D US and their postnatal findings.

\begin{tabular}{lccc}
\hline $\begin{array}{l}\text { Head } \\
\text { Malformation }\end{array}$ & $\begin{array}{c}\text { Detected with } \\
\text { 2D US } \\
\mathrm{n}(\%)\end{array}$ & $\begin{array}{c}\text { Detected with } \\
\text { 3D US (alone) } \\
\mathrm{n}(\%)\end{array}$ & $\begin{array}{c}\text { Postnatally } \\
\text { confirmed } \\
\mathrm{n}(\%)\end{array}$ \\
\hline CNS & $46(95.8 \%)$ & $2(4.2 \%)$ & 48 \\
Face & $11(91.7 \%)$ & $1(8.3 \%)$ & 12 \\
\hline Total & $57(95 \%)$ & $3(5 \%)$ & 60 \\
\hline
\end{tabular}

This table shows that there was statistically significant difference $(p>0.05)$ between both 2D and $3 \mathrm{D}$ ultrasound in detection of head anomalies. However, 3D US was found to be superior to 2D US in detection of both CNS and facial anomalies by ( $4.2 \%$ and $8.3 \%$ respectively). And as a whole, 3D US increased detection of both anomalies over 2D US by $5 \%$. 


\section{Discussion}

Since the first international conference for 3D/4D obstetric and gynecologic US held in Germany 1997, this method has gained a wide acceptance [13]. A consensus conference was held by the American Institute of Ultrasound in Medicine in 2005 , in which it was shown that 3D US has the ability to image an enormous number of obstetrical and gynecologic conditions [14]. However, questions were raised about the role of 3D US in prenatal diagnosis, improving diagnostic accuracy, more anomaly detection and if it can be used routinely in daily practice [15]. Some authors are convinced that $3 \mathrm{D}$ imaging is able to convey additional image information $[\mathbf{9 , 1 0 , 1 6}]$, other authors merely report comparable results [17-19] and similar limitations as with conventional 2D US [11].

In the present work, the detection rates of $2 \mathrm{D}$ US and 3D US were statistically different for postnatally confirmed malformations. 2D US was conformed to 3D US diagnosis in $95 \%$ of the cases. 3D US was more helpful in 5\%.

These results are comparable to those obtained by $\mathrm{Xu}$ et al., [9], who reported higher visualization rates for congenital malformations by 3D US ( $92.7 \%$ versus $78 \%$; McNemar test, $p<0.05$ ). They also found that 3D US was superior to 2D US in $60 \%$ of the definitely diagnosed malformations. In the same vein, Dyson et al., [16] reported on 63 patients with 103 malformations and found that $3 \mathrm{D}$ offered diagnostic advantages in about one half of the cases but only affected management in one patient. They found that 3D US was an adjunctive tool to 2D US providing a more comprehensive image although only to be used as a targeted study to complement 2D US. However, $71 \%$ of the fetal malformations reported in their study were facial $(n=28)$, spinal $(n=10)$ and skeletal abnormalities $(n=36)$ which are reported to be more accurately diagnosed by 3D US.

In contrast, Goncalves et al., [17] examined 99 fetuses (54 were normal and 45 had 82 malformations). They observed conformity between $2 \mathrm{D}$ and $3 \mathrm{D} / 4 \mathrm{D}$ ultrasonography for $90.4 \%$ of the findings. The sensitivity [92.2\% vs. $96.1 \%]$ and specificity [76.4\% vs. $72.7 \%$ ] of 3D/4D and 2D US respectively were insignificantly different (kappa $=0.821$; McNemar-Bowkeris test: 3.00, $p=0.223$ ) in detection of congenital malformations confirmed postnatally. Scharf et al., [11] found that 3D US did not provide significant additional information over what was provided by 2 D US. They reported that the image information that can be acquired by $3 \mathrm{D}$
US is nearly always poorer than the image information that can be obtained by conventional 2D imaging. They stated that the image resolution of the reconstructed planes is inferior to that of the acquisition planes, making the quality of the 2D views that can be obtained traditionally higher than the views that are reconstructed from a 3D volume. They explained that it is merely the examiner brain that perceives the given anomaly in a faster and a more complete way if it is presented in the form of 3D images; it is not the quality of the physical visualization which is rated but the psychological effect which is generated in the examiner brain by the image presentation. Recently, the prospective blinded case-control study of Goncalves et al., [20] included 148 fetuses (58 cases and 90 control) to compare the accuracy of 2D, 3D US and MRI for the diagnosis of fetal congenital malformations, they found that 2D US is more sensitive than 3D US ( $86.2 \%$ and $79.3 \%$ respectively) (McNemar's test, $p=0.046$ ) and both had similar specificities for all malformations $(92.2 \%$ and $94.4 \%$, respectively) (McNemar's test, $p=0.48$ ).

This study showed 3D US as advantageous diagnostic tool especially with head abnormalities and malformations of face. The latter two are often associated with specific curved deformities that cannot be displayed completely on one crosssectional image. It is therefore difficult for conventional 2D US to delineate the 3D shape of these malformations and their relationships to neighboring structures. Hence, misdiagnosis and uncertain diagnosis may easily occur [9]. In contrast, 3D US obtains a volume data set composed of a series of $2 \mathrm{D}$ images and thus is able to conveniently demonstrate the features of the lesions and their spatial relationships $[\mathbf{1 , 2}]$. The reason for this difference is related to the imaging principles and prerequisites of current 3D US. Structures of the fetal cranium/ face and extremities are adjacent to amniotic fluid, with a marked contrast difference between them; hence, these structures are suitable for rendering by the 3D surface mode. Additionally, relatively great contrast differences exist between the fetal bony structures of the extremities and neighboring structures; thus, these structures are suitable for being rendered by the 3D transparent mode. With regard to the internal structures of the fetus, however, only minimal contrast differences exist, and this may lead to an unsatisfactory rendering outcome. To overcome this limitation, the multiplanar mode can be used to observe internal structures from various orientations $[1,2,9]$. In the present study, similar findings were obtained by both 2D and 3D US for neck, thoracic, abdominal, and twin specific malformations. Similarly, Merz et al., [21] 
and XU et al., [9] found 3D US slightly more valuable in diagnosing thoracic and abdominal malformations.

In the present work, 3D US was superior to 2D US in 1 out of 12 cases of facial malformations and 1 out of 48 CNS malformation.

Although in many neonates these deformities are isolated, still, they may be associated with complex genetic and chromosomal syndromes, or acquired embryopathies due to infections, ischemia and toxic exposure $[22,23]$. Consequently, prenatal detection of a facial anomaly should alert the neonatologist to carefully examine the fetus for other malformations and may aid in the management of the pregnancy.

Of the 6 cases of cleft lip/palate identified after birth, 4 cases were correctly identified with both 2D and 3D US and one case was suspected to have only cleft lip by 2D, however, 3D clearly delineated the range and location of the cleft palate. Furthermore, four cases of confirmed micrognathia and three cases of low set ears were diagnosed only by 3D US. Several studies concluded that 3D US provided additional diagnostic information for the detection of facial abnormalities compared to $2 \mathrm{D}$ US [22-25]

Although surface rendering of the face has received most of concern, the three orthogonal planes of the face are not of lesser importance. They enable re-orientation of the fetal face in a standard fashion even with a fetus in unusual positions. This then permits the examiner to view a perfect fetal profile plane as well as a coronal plane regardless of the actual fetal position at the original volume acquisition. In many cases a perfect sagittal view of the profile using $2 \mathrm{D}$ imaging is not possible leading to the erroneous suggestion of micrognathia, flat profile, or other facial abnormalities [1,10]. Merz et al., [22] studied 618 patients between 9 and 37 weeks using both a transvaginal and trans-abdominal approach using the three orthogonal planes. Only in $69 \%$ of the cases was a true midsagittal profile obtained using $2 \mathrm{D}$ scanning only. The 3D reconstructed views allowed a viewing of the perfect midsagittal profile in all cases. There were a total of 25 facial malformations 20 of which were clearly detected both in 2 and 3D US whereas in 5 cases there were additional features identified using only 3D US.

Moreover, visualizing the corpus callosum is challenging in imaging the fetal brain, and this is where 3D US proves to be of benefit through the use of the multiplanar mode which allows a more accurate identification of the midsagittal plane and navigation in the other two orthogonal planes simultaneously $[\mathbf{7 , 2 6 ]}$. In other studies, 3D US allowed better characterization of vermian abnormalities through evaluating the posterior fossa and vermian morphometry [27,28]. In Correa et al., study, 3D US was superior to 2D for visualization of the trans-cerebellar axial plane in 202 fetuses in mid-trimester scans [13].

\section{Conclusions:}

Three dimensional US significantly improved the number of detected fetal malformations, than that detected by 2D US. Three-dimensional imaging is superior in specific diagnostic problems. It has to be emphasized that, rather than representing an alternative, the 3D US is complementary to the conventional 2D sonography in the field of prenatal diagnosis. It can be regarded as a state of the art technology with an important role, yet from an economic and scientific standpoint, a broad implementation (e.g. screening tests) of 3D US cannot be recommended. Its application is recommended to be restricted to tertiary referral centers where further research work is necessary to assign a clearly defined range of indications to 3D US.

\section{Declarations:}

- Consent for publication: Not applicable.

-Availability of data and material: All data generated or analyzed during this study are included in this published article.

- Competing interests: The authors declare that they have no competing interests.

- Funding: None.

-Acknowledgements: Not applicable.

\section{References}

1- GONÇALVES L.F., LEE W., ESPINOZA J. and ROMERO R.: Three- and 4-dimensional ultrasound in obstetric practice does it help? Journal of Ultrasound in Medicine, 24: 1599-624, 2005.

2- BENACERRAF B.R.: Three-dimensional fetal sonography: Use and misuse. Journal of Ultrasound in Medicine, 21: 1063-7, 2002.

3- RUANO R., MARTINOVIC J., DOMMERGUES M., AUBRY M.C., DUMEZ Y. and BENACHI A.: Accuracy of fetal lung volume assessed by three-dimensional sonography. Ultrasound Obstet. Gynecol., 26: 725-30, 2005.

4- KALACHE K.D., EDER K., ESSER T., PROQUITTÉ H., STOLTENBURG-DIDINGER G., HARTUNG J.P., et al.: Three-dimensional ultrasonographic reslicing of the fetal brain to assist prenatal diagnosis of central nervous system anomalies. J. Ultrasound Med., 25: 509$14,2006$. 
5- BERGANN A., BAMBERG C., EDER K., PROQUITTÉ H., HARTUNG J.P., BOLLMANN R., et al.: Mid-facial anthropometry in second-trimester fetuses with trisomy 21: A three-dimensional ultrasound study. Prenat. Diagn., 26: $158-62,2006$.

6- DeVORE G.R., FALKENSAMMER P., SKLANSKY M.S. and PLATT L.D.: Spatio-temporal image correlation (STIC): New technology for evaluation of the fetal heart. Ultrasound Obstet. Gynecol., 22: 380-7, 2003.

7- MALINGER G., LERMAN-SAGIE T. and VIÑALS F.: Three-dimensional sagittal reconstruction of the corpus callosum: Fact or artifact? [4]. Ultrasound in Obstetrics and Gynecology, 28: 742-3, 2006.

8- JI E.K., PRETORIUS D.H., NEWTON R., UYAN K., HULL A.D., HOLLENBACH K., et al.: Effects of ultrasound on maternal-fetal bonding: A comparison of twoand three-dimensional imaging. Ultrasound Obstet. Gynecol., 25: 473-7, 2005.

9- XU H.X., ZHANG Q.P., LU M. De and XIAO X.T. Comparison of two-dimensional and three-dimensional sonography in evaluating fetal malformations. J. Clin. Ultrasound., 30: 515-25, 2002.

10- MERZ E. and WELTER C.: 2D and 3D ultrasound in the evaluation of normal and abnormal fetal anatomy in the second and third trimesters in a level III center. Ultraschall der Medizin, 26: 9-16, 2005.

11- SCHARF A., GHAZWINY M.F., STEINBORN A. and BAIER P. SOHN C.: Evaluation of two-dimensional versus three-dimensional ultrasound in obstetric diagnostics: A prospective study. Fetal Diagn. Ther., 16: 333-41, 2001.

12- SALOMON L.J., ALFIREVIC Z., BERGHELLA V., BILARDO C., HERNANDEZ-ANDRADE E., JOHNSEN S.L., et al.: Practice guidelines for performance of the routine mid-trimester fetal ultrasound scan. Ultrasound Obstet. Gynecol., 37: 116-26, 2011.

13- MERZ E. and ABRAMOWICZ J.S.: 3D/4D ultrasound in prenatal diagnosis: Is it time for routine use? Clin. Obstet. Gynecol., 55: 336-51, 2012.

14- BENACERRAF B.R., BENSON C.B., ABUHAMAD A.Z., COPEL J.A., ABRAMOWICZ J.S., DEVORE G.R., et al.: Three-and 4-dimensional ultrasound in obstetrics and gynecology: Proceedings of the American institute of ultrasound in medicine consensus conference. In: Journal of Ultrasound in Medicine, p. 1587-97, 2005.

15-MERZ E.: Current 3D/4D ultrasound technology in prenatal diagnosis. Eur. Clin. Obstet. Gynaecol., 1: 184-93, 2005

16- DYSON R.L., PRETORIUS D.H., BUDORICK N.E., JOHNSON D.D., SKLANSKY M.S., CANTRELL C.J., et al.: Three-dimensional ultrasound in the evaluation of fetal anomalies. In: Ultrasound in Obstetrics and Gynecology, p. 321-8, 2000.

17- GONÇALVES L.F., NIEN J.K., ESPINOZA J., KUSANOVIC J.P., LEE W., SWOPE B., et al.: What does 2- dimensional imaging add to 3-and 4-dimensional obstetric ultrasonography? J. Ultrasound Med., 25: 691-9, 2006.

18- JOHNSON D.D., PRETORIUS D.H., RICCABONA M., BUDORICK N.E. and NELSON T.R.: Three-dimensional ultrasound of the fetal spine. Obstet. Gynecol. Surv., 89: 434-8, 1997.

19- PRETORIUS D.H. and NELSON T.R.: Fetal face visualization using three-dimensional ultrasonography. J. Ultrasound Med., 14: 349-56, 1995.

20- GONÇ ALVES L.F., LEE W., MODY S., SHETTY A., SANGI-HAGHPEYKAR H., ROMERO R., et al.: Diagnostic accuracy of ultrasonography and magnetic resonance imaging for the detection of fetal anomalies: A blinded case--control study. Ultrasound Obs. Gynecol., 48: 18592, 2016.

21- MERZ E., BAHLMANN F. and WEBER G.: Volume scanning in the evaluation of fetal malformations: A new dimension in prenatal diagnosis. Ultrasound Obstet. Gynecol., 5: 222-7, 1995.

22- MERZ E., WEBER G., BAHLMANN F. and MIRICTESANIC D.: Application of transvaginal and abdominal three-dimensional ultrasound for the detection or exclusion of malformations of the fetal face. Ultrasound in Obstetrics and Gynecology, 9: 237-43. doi: 10.1046/j.1469-0705. 1997.09040237.x, 1997.

23- BENACERRAF B.R. and MULLIKEN J.B.: Fetal cleft lip and palate: Sonographic diagnosis and postnatal outcome. Plast. Reconstr. Surg., 92: 1045-51, 1993.

24- JOHNSON D.D., PRETORIUS D.H., BUDORICK N.E., JONES M.C., LOU K.V., JAMES G.M., et al.: Fetal lip and primary palate: Three-dimensional versus twodimensional US. Radiology, 217: 236-9, 2000.

25- LEE W., McNIE B., CHAIWORAPONGSA T., CONOSCENTI G., KALACHE K.D., VETTRAINO I.M., et al. Three-dimensional ultrasonographic presentation of micrognathia. J. Ultrasound Med., 21: 775-81, 2002.

26- PLASENCIA W., DAGKLIS T., BORENSTEIN M., CSAPO B. and NICOLAIDES K.H.: Assessment of the corpus callosum at 20-24 weeks' gestation by threedimensional ultrasound examination. Ultrasound Obstet. Gynecol., 30: 169-72, 2007.

27- VOLPE P., CONTRO E., De MUSSO F., GHI T., FARINA A., TEMPESTA A., et al.: Brainstem-vermis and brainstem-tentorium angles allow accurate categorization of fetal upward rotation of cerebellar vermis. Ultrasound Obstet. Gynecol., 39: 632-5, 2012.

28- PALADINI D. and VOLPE P.: Posterior fossa and vermian morphometry in the characterization of fetal cerebellar abnormalities: A prospective three-dimensional ultrasound study. Ultrasound Obstet. Gynecol., 27: 482-9, 2006.

29- CORREA F.F., LARA C., BELLVER J., REMOHÍ J., PELLICER A. and SERRA V.: Examination of the fetal brain by transabdominal three-dimensional ultrasound: Potential for routine neurosonographic studies. Ultrasound Obstet. Gynecol., 27: 503-8, 2006. 


\section{القيمة المضافة للموجات فوق الصوتية ثلاثية الآبعاد فى تقييهم ما قبل الولادة للتشوهات الجنينية العصبية والهوتية والجهاز العصبى الهركزي}

آحد المبردات الآكثر إستخداماً لإستخدام الموجات فوق الصوتية للولادة هو آن التشخيص الدقيق لتشوهات الجنين قبل الولادة يمكن آن

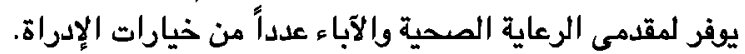

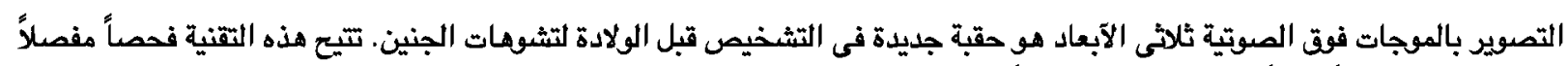

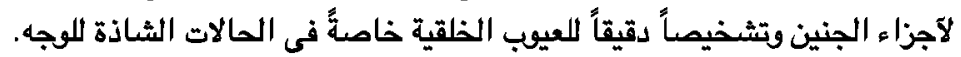

تم إختراع تقنيات متعددة فى السنوات الآخيرة، مثل الوضع متعدد الطبقات، وطريقة عرض السطح والتصوير الحى عالى الدقة، والتصوير المقطعى بالموجات فوق الصوتية.

هدفنا فى الدراسة هو إظهار القيمة المضافة الموجات فوق الصوتية ثالاثية الآبعاد فى التشخيص قبل الولادة لتشوهات الجنين.

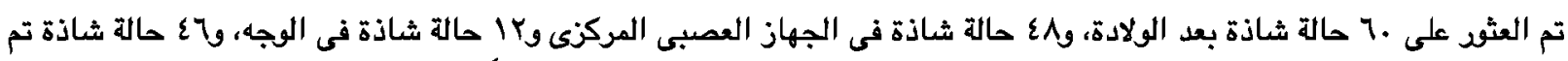

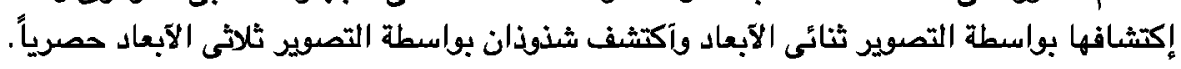

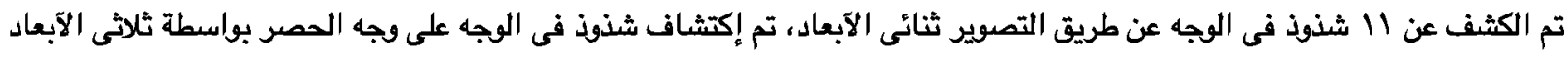

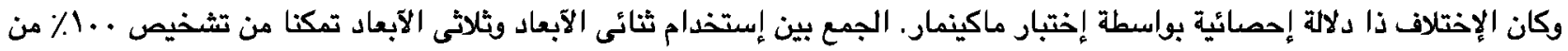

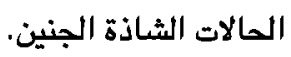

